\title{
Autosomal dominant epilepsy with auditory features
}

INSERM

\section{Source}

INSERM. (1999). Orphanet: an online rare disease and orphan drug data base. Autosomal dominant epilepsy with auditory features. ORPHA:101046

A rare, genetic, familial partial epilepsy disease characterized by focal seizures associated with prominent ictal auditory symptoms, and/or receptive aphasia, presenting in two or more family members and having a relatively benign evolution. 